\title{
The Extent of Non - Nursing Tasks and Their Impact on Quality Patient Care As Perceived By Nurses in Al Dakhliyah Governorate, Oman
}

Sabir Abdullah Al Amri ${ }^{*}$, Jonas Dupo ${ }^{2}$, Mouna Mohana Al Kindi ${ }^{3}$, Radhiya Sulayem Al Tobi ${ }^{4}$, Sawsan Mohammed BaniOraba $^{4}$, Gayhart Torrano ${ }^{5}$, Fatima Mohammed Al Amri ${ }^{4}$, Fawzia Issa Al Aamri ${ }^{4}$

${ }^{1}$ Nursing In Charge, Izki Hospital, Al Dakhliyah Governorate, Oman

${ }^{2}$ Regional Nursing Research Focal Point, Directorate of Nursing, Oman

${ }^{3}$ Nursing In Charge, Farq Health Center, Nizwa, Oman

${ }^{4}$ Staff Nurse, Izki Hospital, Oman

${ }^{5}$ Staff Nurse, Nizwa Polyclinic, Nizwa, Oman

DOI: $10.36348 /$ SJNHC.2019.v02i09.005

*Corresponding author: Sabir Abdullah Al Amri
| Received: 29.08.2019 | Accepted: 05.09.2019 | Published: 22.09.2019

Email: std_izki@yahoo.com

\section{Abstract}

Objective: The study aimed to establish the most common non - nursing tasks performed by nurses and its impact on the delivery of nursing care in Al Dakhliyah Governorate Oman in select government hospitals. Methods: This study is cross-sectional involving 173 nurses from June to July 2018 through stratified random sampling. The questionnaire was based on different literature specifically the RN FORECAST questionnaire utilized in European studies. The results were analyzed through the use of SPSS version 21 through means and frequency distribution. Results: Out of $n=173$ respondents, 164 answered the questionnaire with a response rate of $94.74 \%$. The top five most common non-nursing tasks are answering phones and clerical (3.38 times per person), filling of items such as syringe, incontinent sheet, gauze and cotton (3.36 times), cleaning of medical equipment (3.20 times), bringing sample to the laboratory (2.96 times) and transporting of patients within the hospital (2.76 times). On the other hand, the top missed care include oral hygiene $(60 \%) \&$ nurse-patient interaction (60\%), physical assessment $(59.21 \%)$, frequent changing of position $(58.87 \%)$ and proper documentation (56.68\%). Conclusion: The nurses working in the government institutions in Al Dakhliyah governorate performs numerous non-nursing tasks which affect the delivery of patient care. As a recommendation, a clerk should be included as non-healthcare personnel responsible for many non-nursing tasks. To offer an assistant for nurses, a nursing aid is also recommended as a member of the healthcare team. Additionally, the medical orderly should also be oriented and updated on their job descriptions.

Keywords: Nursing Tasks, Al Dakhliyah Governorate, RN FORECAST.

Copyright @ 2019: This is an open-access article distributed under the terms of the Creative Commons Attribution license which permits unrestricted use, distribution, and reproduction in any medium for non-commercial use (NonCommercial, or CC-BY-NC) provided the original author and source are credited.

\section{INTRODUCTION OR BACK GROUND}

Non - nursing tasks were defined as tasks not requiring professional nursing training and that should be assigned or delegated to other staff and should be removed from nurse's job responsibilities [1]. On the other hand, non - nursing tasks are considered a barrier to the delivery of nursing care management. As defined "non - nursing tasks are tasks performed by professional nurses below their scope of practice [2].

Nurses in the hospitals in Oman often encounter these issues but no studies have been conducted to explore this concerned area in nursing. Nurses are considered professionals with crucial roles in the healthcare field. The primary roles of nurses are adapting the nursing process allowing critical thinking skills in every patient[3]. Few studies explored the most common non - nursing tasks being carried out by nurses in the hospitals. Lifted from the RN4CAST study in Europe [4], the following non nursing tasks were identified; delivering and retrieving food trays, performing non - nursing tasks, arranging discharge referral and transportation, routine phlebotomy, and blood tests, transporting of patients within hospital, cleaning patient's room and equipment, filling on for non - nursing service not available of hours, obtaining supply and equipment and answering phones and clerical duties.

In the International health care setting such as the United States of America, nursing services 
comprises of registered nurses, licensed practical nurses and nursing aides including medical orderlies. American Nurses Association (ANA) presented responsibilities of registered nurses such as performing physical examinations, health histories, offering health promotion and counseling, administering medications, wound care and other personalized interventions, interpret patient information and make critical decisions, coordinate care in collaboration with different professionals, direct and supervise other health care professionals like licensed practical nurse and nursing aides and conduct research on patient outcomes. Licensed Practical Nurses (LPN's) are also known as licensed vocational nurse who offers basic and routine care consistent with their education [5].

In the Sultanate of Oman, the available healthcare workers include Registered Nurses and Medical orderlies. This differs from other institutions from other countries having registered nurses, licensed practical nurses, nursing aides, and medical orderlies. Most of the non - nursing tasks being performed by nurses are also part of the job descriptions of other health care workers in the area. Some of the highlighted job descriptions of a grade 10 medical orderly were; assists in the performance of cleanliness activities to maintain safe, clean, tidy and effective patient care environment, assists with the transport of patients, notes, specimens, and investigations and finally assists in assessing the stock requirements for disposable and non - disposable items, maintaining an inventory of items and storing items in a designated places [6].

Workload and understaffing can influence the performance of non - nursing tasks. Heekang emphasized that if nurses are doing heavy workload, it can cause a burden towards the nursing staff which can affect the delivery of care that requires professional skills [7]. In the Sultanate of Oman, there is no study exploring the prevalence of non - nursing task and also the missed care. Therefore, this study aimed to establish the most common non - nursing task performed by nurses and its effects on the delivery of nursing care in Al Dakhliyah Governorate select government hospitals.

\section{MATERIAL AND METHODS}

This study is a descriptive cross-sectional study conducted between June and July 2018 in five governmental hospitals in Al Dakhliyah Governorate. The total population of nurses working in Al Dakhliyah Governorate health care institutions are $N=1259$; Nizwa Hospital $(n=622)$, and 28 health Institutions (local hospitals, polyclinic and health centers, $n=637$ ). Out of the total population, only five hospitals were included with a total population of $n=312$. Based on Slovin's formula, the target population is 173 .

Stratified random sampling was used to recruit nurses to participate in the study. All nurses working full time in the selected hospitals with 1 year of experience were included. Nurses who are not involved in direct patient care were excluded in the study such as working in nursing administration, infection control, and quality assurance. The study utilized a new questionnaire based on the RN FORECAST questionnaire. The questionnaire has three parts including demographic data, the prevalence of non nursing task and the missed care. The demographics include institution, age, gender, civil status, educational attainment, nationality, total years of experience and ward assignment. There are 20 non-nursing task questions which were answered by frequency such as 1 , 2, 3, 4 or more than 5. Regarding the prevalence of missed care, there are 15 selected possible missed care which was answered via yes, no, or not applicable.

After the ethical approval from RERAC, the researchers sent a communication letter to all the selected healthcare institutions specifying the intent of data collection and that nurses are randomly invited to participate. However, the participants are oriented that their participation is highly voluntary. The total questionnaire distributed is 173 .

The study utilized the Statistical Package for Social Sciences Software for Windows (Version 23.0; IBM Corp., Armonk, NY, USA). The study also used descriptive statistics to get mean and frequency distribution. The Research and Ethical Review and Approve Committee from the Ministry of Health's Centre of Studies and Research approved the study. The researchers ensured that the data gathered are confidential and the participation of the respondents is highly voluntary. A consent form was attached from each questionnaire including the purpose of the study and whether they understand and they have been assisted.

\section{Findings}

Out of 173 invited respondents, the total response rate is $n=164$ (response rate of $94.79 \%$ ). Majority of the respondents are from Sumail Hospital (41.5\%), their mean age is 31.9, female $(90.2 \%)$ and married $(93.9 \%)$. Additionally, most of the respondents have a Diploma degree $(67.1 \%)$, Omani citizens $(70.1 \%)$ and working in the Accident and Emergency department (25.6\%). Lastly, the average year of experience is 10.13 years (Table-1). 
Table-1: Demographic Profile of the respondents

\begin{tabular}{|c|c|c|c|}
\hline No & Variable & Frequency & Percentage \\
\hline \multirow[t]{6}{*}{1} & Institution & & \\
\hline & Bahla Hospital & 34 & $20.7 \%$ \\
\hline & Adam Hospital & 24 & $14.6 \%$ \\
\hline & Sumail Hospital & 68 & $41.5 \%$ \\
\hline & Izki Hospital & 28 & $17.1 \%$ \\
\hline & JabalAkdhar & 10 & $6.1 \%$ \\
\hline 2 & $\begin{array}{l}\text { Age } \\
\text { Mean: } 31.99 \\
\text { Standard Deviation: } 5.68\end{array}$ & & \\
\hline \multirow[t]{3}{*}{3} & Gender & & \\
\hline & Male & 16 & $9.8 \%$ \\
\hline & Female & 148 & $90.2 \%$ \\
\hline \multirow[t]{5}{*}{4} & Civil Status & & \\
\hline & Single & 8 & $4.9 \%$ \\
\hline & Married & 154 & $93.9 \%$ \\
\hline & Widow & 1 & $0.6 \%$ \\
\hline & Divorce & 1 & $0.6 \%$ \\
\hline \multirow[t]{5}{*}{5} & Educational attainment & & \\
\hline & Diploma & 110 & $67.1 \%$ \\
\hline & Post Diploma & 27 & $16.5 \%$ \\
\hline & Baccalaureate & 26 & $15.9 \%$ \\
\hline & Master Degree & 1 & $0.6 \%$ \\
\hline \multirow[t]{7}{*}{6} & Nationality & & \\
\hline & Omani & 115 & $70.1 \%$ \\
\hline & Indian & 34 & $20.7 \%$ \\
\hline & Filipino & 12 & $7.3 \%$ \\
\hline & Tunisian & 1 & $0.6 \%$ \\
\hline & Bangladeshi & 1 & $0.6 \%$ \\
\hline & Pakistani & 1 & $0.6 \%$ \\
\hline 7 & $\begin{array}{l}\text { Total Years of Experience } \\
\text { Mean: } 10.13 \\
\text { Standard Deviation: } 4.58\end{array}$ & & \\
\hline \multirow[t]{10}{*}{8} & Ward Assignment & & \\
\hline & $\mathrm{A} \& \mathrm{E}$ & 42 & $25.6 \%$ \\
\hline & Female Ward & 24 & $14.6 \%$ \\
\hline & Pediatric Ward & 12 & $7.3 \%$ \\
\hline & Renal Medicine Unit & 10 & $6.1 \%$ \\
\hline & Labor Room & 11 & $6.7 \%$ \\
\hline & General Ward & 34 & $20.7 \%$ \\
\hline & Male Ward & 17 & $10.4 \%$ \\
\hline & Male Ward \& P.W. & 7 & $4.3 \%$ \\
\hline & Female Ward, LR, Maternity & 7 & $4.3 \%$ \\
\hline
\end{tabular}

Table-2 shows the prevalence of non-nursing task. The top five most prevalent non - nursing task include 1) answering phones and clerical duty (3.38 times per person in the last 5 days), 2) filling of items such as syringe, incontinent sheet, gauze and cotton
(3.36 times), 3) Cleaning of medical equipment (3.20 times), bringing sample to the laboratory (2.96 times) and transporting of patients within the hospital $(2.76$ times). 
Table-2: Prevalence of Non Nursing task

\begin{tabular}{|l|l|l|l|l|}
\hline No. & Non Nursing Task in the last (5) five days & Total & Prevalence per person & Rank \\
\hline 1 & Delivering and retrieving food trays & 268 times & 1.79 & 17 \\
\hline 2 & Arranging discharge referrals and transportation & 423 times & 2.69 & 6 \\
\hline 3 & Transporting of patients within the hospital & 440 times & 2.76 & 5 \\
\hline 4 & Cleaning Patient's Room & 395 times & 2.51 & 7 \\
\hline 5 & Filling in for non- nursing services not available during off hours & 268 times & 1.92 & 16 \\
\hline 6 & Obtaining supplies and equipment & 384 times & 2.46 & 9 \\
\hline 7 & Answering phones and clerical duties & 551 times & 3.38 & 1 \\
\hline 8 & Communicating for damage equipment for repair & 391 times & 2.45 & 10 \\
\hline 9 & Monthly delivery of all hospital delivery system & 237 times & 1.63 & 19 \\
\hline 10 & Reviewing total stocks & 337 times & 2.16 & 13 \\
\hline 11 & Filling out medico legal forms for cashier & 258 times & 1.75 & 18 \\
\hline 12 & Bringing sample to the laboratory & 478 times & 2.96 & 4 \\
\hline 13 & Bringing materials for autoclave & 383 times & 2.50 & 8 \\
\hline 14 & Preparing gauze and cotton & 362 times & 2.27 & 12 \\
\hline 15 & Filling of items (syringe, incontinent sheet, gauze and cotton) & 548 times & 3.36 & 2 \\
\hline 16 & Cleaning of medical equipment & 512 times & 3.20 & 3 \\
\hline 17 & Photocopy of forms and other papers & 384 times & 2.43 & 11 \\
\hline 18 & Security and PRO work & 315 times & 2.00 & 15 \\
\hline 19 & Assisting in the x ray room for radiologic procedures & 337 times & 2.10 & 14 \\
\hline 20 & Checking and maintaining the mortuary room & 156 times & 1.06 & 20 \\
\hline
\end{tabular}

The respondents were asked to identify the following nursing care that they missed because of nonnursing task. Out of 15 care being offered to patients, the top five include oral hygiene (60\%), physical assessment $(59.21 \%)$, frequent changing of position $(58.87 \%)$, proper documentation $(56.68 \%)$ and planning of care $(56.20 \%)$ (Table-3).

Table-3: Prevalence of Missed Care

\begin{tabular}{|l|l|l|l|l|}
\hline No. & Missed Care & n & Prevalence & Rank \\
\hline 1 & Documentation & 157 & $56.68 \%$ & 4 \\
\hline 2 & Skin Care & 134 & $55.22 \%$ & 7 \\
\hline 3 & Oral Hygiene & 130 & $60.00 \%$ & 1 \\
\hline 4 & Physical Assessment & 152 & $59.21 \%$ & 2 \\
\hline 5 & Medication administration & 154 & $44.15 \%$ & 12 \\
\hline 6 & Educating the patient & 153 & $53.59 \%$ & 8 \\
\hline 7 & Pain assessment and management & 154 & $55.84 \%$ & 6 \\
\hline 8 & Planning of care & 153 & $56.20 \%$ & 5 \\
\hline 9 & Frequent changing of position & 124 & $58.87 \%$ & 3 \\
\hline 10 & Wound care and dressing & 140 & $44.28 \%$ & 11 \\
\hline 11 & Admission and discharge & 145 & $37.93 \%$ & 14 \\
\hline 12 & Nurse Patient Interaction & 160 & $60.00 \%$ & 1 \\
\hline 13 & Vital signs checking & 159 & $44.65 \%$ & 13 \\
\hline 14 & Discussion with physician regarding plan of care & 157 & $52.86 \%$ & 9 \\
\hline 15 & Patient safety precautions & 156 & $50.64 \%$ & 10 \\
\hline
\end{tabular}

\section{DISCUSSION}

In one study, the most common non - nursing tasks being carried were, transporting of a patient, delivering and retrieving food trays and housekeeping duties [7]. An additional finding is that $6.8-9.1$ out of 10 nurses had performed non - nursing tasks [7]. In one study, the four main non - nursing tasks identified were answering phones, clerical duties, arranging discharge referrals and transport and performing non - nursing tasks [4]. In a study involving 12 European countries, it was noted clerical duties comprises of the highest nonnursing tasks in England (99.7\%) and Sweden (94.6\%) [2]. Finally, nurses are also utilizing their time on activities that are not related to patient care which includes some household tasks, administration, taking care of supplies and training students [8].
Professional nurses level one entry or General Nurses in the Sultanate of Oman have the following job descriptions. Nurses' clinical roles are assisting in assessment, planning implementation and evaluation of nursing care, educates patient and client group about preventive measures, communicates effectively, maintains accurate records of patients, comply with Ministry of Health policies and perform blood collection procedure according to infection control policy as required [6].

Finally, the Sultanate of Oman has diverged group of healthcare workers in the nursing workforce such as groups coming from the Philippines, India, Tunisia and Bangladesh [9]. In line with the foreign 
workers in Oman, it has been noted that nurses who came from developing countries working in European Hospitals tend the non - nursing tasks in their last shift [2]. This finding might influence the result of the study since expatriates are included in this study.

The use of nurses' time and energy is crucial in the healthcare system [2]. Especially that nurses are handling life and handling complex life - saving responsibilities. Professional nursing roles should be upheld at all times. Another important concept of nurses' roles is identifying the most common technical and non -technical tasks of nurses. The most common nurses' non - technical tasks were investigation review, history acquisition, contribution to the management plan and explanation to bedside nurses and other members of the healthcare team. Technical tasks were examining the circulation, conscious state and chest. This study proved that nurses are focusing on their professional roles and responsibilities [10]. Related to the quality of care, it was reported that $73.4 \%$ of nurses were missing at least one nursing activity on their last shift [11]. This number represents a huge percentage of nurses impacting the quality of patient care.

In the Middle East, one study conducted in Kuwait exploring the nursing activities and care left undone in an Arab health care system which is somehow similar to the health care system in Oman. The most common nursing activities noted were administrations of medications, assessing patient condition, preparing/updating nursing care plans, close patient monitoring and client health teaching [12]. One of the aspects focus in this study is the relationship on non - nursing tasks to the quality of care or care left undone. To which, from previous studies, there was a strong correlation between the non - nursing tasks and care left undone[4], which means that when a nurse is busy doing responsibilities out of her professional job, there is a tendency of missing the necessary care that should be provided and delivered to the patients. Concerning the environment, missed care was more common in a poor healthcare environment [11].

In the RN4CAST study conducted in Europe, the following are the most common nursing tasks left undone such as patient surveillance, skincare, oral hygiene, pain management, comfort/talk with the patients, educating patients and family, treatments and procedures, administering medications on time, preparing families patients and families for discharge, nursing documentation, updating nursing care plans, planning of care and frequent change of position [13]. The results of this multi-country study is similar to the result of our study.

These nursing tasks were projected to have a direct effect on patient satisfaction, delivery of quality care and an overall impact of care. Because of these non - nursing activities, there are nursing tasks that were left undone. Out of 8 studies conducted exploring the different care undone from Europe to America, the Middle East, and Africa, most studies have the same findings, which is also almost similar to the result of our study. The most common care left undone is talking or comforting the patient $[4,1,14,12,15,11,16]$ which is followed by either educating the patient $[4,1,16]$ or updating the nursing care plans $[4,1,14,11]$. Additional left not being able to carry out by nurses are the following documentation of nursing care, oral hygiene, routine care and changing of IV fluid [12].

Workload and understaffing can influence the performance of non - nursing tasks. It was emphasized that if nurses are doing heavy workload, it can cause a burden towards the nursing staff which can affect the delivery of care that requires professional skills [7]. Majority of the nurses included in our study missed the crucial nursing care such as nurse patient interaction, documentation, medication administration and even safety precautions. Additionally, the unfinished care or missed care by nurses have an impact on the overall quality of patient care [14]. Moreover, if the work environment has improved, there are positive outcomes of overall health [17]. This alone should serve as a motivation, so that the government healthcare institution in $\mathrm{Al}$ Dakhliyah Governorate will create programs in reducing the performance of non-nursing tasks.

Many studies also discovered correlations between lower levels of nurse staffing or understaffing and occurrences of some medical problems of patients such as higher rates of pneumonia, upper gastrointestinal bleeding, shock/cardiac arrest, urinary tract infections, and failure to rescue [18]. Moreover, when nurses focus on their non - nursing tasks, there is a perceived effect on the following variables; falls, nosocomial infection, pressure sores and medication error [7]. The most crucial study conducted by Ball et $a l$., on postoperative mortality is the association of lower staffing missed the care and patient mortality wherein each $10 \%$ of the increase in the missed care, there is a $16 \%$ probability that patient might die after a surgery [14].

This study is cross-sectional in nature has already a limitation. It also targets one governorate only, has a relatively low number of respondents who do not represent the whole population. It is recommended that studies on non-nursing tasks should be conducted especially in the tertiary hospitals in Oman and in other governorates. Moreover, the questionnaire is also new and is recommended to have a valid, tested and strong questionnaire that can offer a deeper statistical analysis in the future.

\section{CONCLUSION}

The nurses working in the government institutions in $\mathrm{Al}$ Dakhliyah governorate performs 
numerous non-nursing tasks which affect the delivery of patient care. As a recommendation, a clerk should be included as non-healthcare personnel responsible for many non-nursing tasks. To offer an assistant for nurses, a nursing aid is also recommended as a member of the healthcare team. Additionally, the medical orderly should also be oriented on their job descriptions.

Conflict of Interest: There is no conflict of interest in this study.

Source of Funding- self or other Source: No funding was received in this study.

Ethical Clearance: The Research and Ethical Review and Approved Committee Al Dakhliyah Governorate, Ministry of Health, Oman approved on May 6, 2018.

\section{REFERENCES}

1. Ausserhofer, D., Zander, B., Busse, R., Schubert, M., De Geest, S., Rafferty, A. M., ... \& Sjetne, I. S. (2014). Prevalence, patterns and predictors of nursing care left undone in European hospitals: results from the multicountry cross-sectional RN4CAST study. BMJ quality \& safety, 23(2), 126-135.

2. Bruyneel, L., Li, B., Aiken, L., Lesaffre, E., Van den Heede, K., \& Sermeus, W. (2013). A multicountry perspective on nurses' tasks below their skill level: reports from domestically trained nurses and foreign trained nurses from developing countries. International Journal of Nursing Studies, 50(2), 202-209.

3. Benner, P., Hughes, R. G., \& Sutphen, M. (2008). Clinical reasoning, decisionmaking, and action: Thinking critically and clinically. In Patient safety and quality: An evidence-based handbook for nurses. Agency for Healthcare Research and Quality (US). Available from: https://www.ncbi.nlm.nih.gov/books/NBK2643/

4. Bekker, M., Coetzee, S. K., Klopper, H. C., \& Ellis, S. M. (2015). Non-nursing tasks, nursing tasks left undone and job satisfaction among professional nurses in $\mathrm{S}$ outh $\mathrm{A}$ frican hospitals. Journal of nursing management, 23(8), 1115-1125.

5. What is Nursing \& What do nurses do? I ANA Enterprise [Internet]. ANA. 2019 [cited 22 August 2019]. Available from: https://www.nursingworld.org/practicepolicy/workforce/what-is-nursing/

6. Ministry of Health, Sultanate of Oman (2015). Generic Job Descriptions for medical orderly and General Nurse.

7. Kang, J. H., Kim, C. W., \& Lee, S. Y. (2016). Nurse-perceived patient adverse events depend on nursing workload. Osong public health and research perspectives, $7(1), 56-62$.
8. van den Oetelaar, W. F. J. M., Van Stel, H. F., Van Rhenen, W., Stellato, R. K., \& Grolman, W. (2016). Balancing nurses' workload in hospital wards: study protocol of developing a method to manage workload. BMJ open, 6(11), e012148.

9. Department of Health Information \& Statistics, Directorate General of Planning and Studies, Ministry of Health, Sultanate of Oman. (2017). Annual Health Report of 2016.

10. Topple, M., Ryan, B., Baldwin, I., McKay, R., Blythe, D., Rogan, J., ... \& Jones, D. (2016). Tasks completed by nursing members of a teaching hospital Medical Emergency Team. Intensive and Critical Care Nursing, 32, 12-19.

11. Lake, E. T., Germack, H. D., \& Viscardi, M. K. (2016). Missed nursing care is linked to patient satisfaction: a cross-sectional study of US hospitals. BMJ Qual Saf, 25(7), 535-543.

12. Al-Kandari, F., \& Thomas, D. (2009). Factors contributing to nursing task incompletion as perceived by nurses working in Kuwait general hospitals. Journal of clinical nursing, 18(24), 34303440 .

13. Sermeus, W., Aiken, L. H., Van den Heede, K., Rafferty, A. M., Griffiths, P., Moreno-Casbas, M. T., ... \& Brzostek, T. (2011). Nurse forecasting in Europe (RN4CAST): rationale, design and methodology. BMC nursing, 10(1), 6.

14. Ball, J. E., Murrells, T., Rafferty, A. M., Morrow, E., \& Griffiths, P. (2014). 'Care left undone'during nursing shifts: associations with workload and perceived quality of care. BMJ Qual Saf,23(2), 116-125.

15. Zander, B., Dobler, L., Bäumler, M., \& Busse, R. (2014). Nursing tasks left undone in German acute care hospitals-results from the international study RN4Cast. Gesundheitswesen (Bundesverband der Arzte des Offentlichen Gesundheitsdienstes (Germany)), 76(11), 727-734.

16. Carthon, J. M. B., Lasater, K. B., Sloane, D. M., \& Kutney-Lee, A. (2015). The quality of hospital work environments and missed nursing care is linked to heart failure readmissions: a crosssectional study of US hospitals. BMJ Qual Saf, 24(4), 255-263.

17. Aiken, L. H., Sermeus, W., Van den Heede, K., Sloane, D. M., Busse, R., McKee, M., ... \& Tishelman, C. (2012). Patient safety, satisfaction, and quality of hospital care: cross sectional surveys of nurses and patients in 12 countries in Europe and the United States. Bmj, 344, e1717.

18. Stanton, M. W., \& Stanton, M. W. (2004). Hospital nurse staffing and quality of care (pp. 04-0029). Rockville, MD: Agency for Healthcare Research and Quality. Research in Action Issue 14. AHRQ Pub. No. 04-0029 Retrieved from https://archive.ahrq.gov/research/findings/factsheet s/services/nursestaffing/nursestaff.pdf 